\title{
Physiotherapist-led treatment for young to middle- aged active adults with hip-related pain: consensus recommendations from the International Hip-related Pain Research Network, Zurich 2018
}

\author{
Joanne L Kemp 이, ${ }^{1}$ May Arna Risberg, ${ }^{2,3}$ Andrea Mosler, ${ }^{1}$ Marcie Harris-Hayes ำ , 4,5 \\ Andreas Serner (1) ${ }^{6}{ }^{6}$ Håvard Moksnes, ${ }^{7}$ Nancy Bloom, ${ }^{4,5}$ Kay M Crossley (1) , \\ Boris Gojanovic 이, ${ }^{8,9}$ Michael A Hunt, ${ }^{10}$ Lasse Ishøi (ㄷ, , ${ }^{11}$ Nicolas Mathieu, ${ }^{12}$ \\ Sue Mayes, ${ }^{1,13}$ Mark J Scholes, ${ }^{1}$ Mo Gimpel, ${ }^{14}$ Daniel Friedman, ${ }^{15}$ Eva Ageberg @,${ }^{16}$ \\ Rintje Agricola, ${ }^{17}$ Nicola C Casartelli ${ }^{1}\left({ }^{18,19}\right.$ Laura E Diamond ${ }^{10},{ }^{20}$ \\ H Paul Dijkstra, ${ }^{21,22}$ Stephanie Di Stasi, ${ }^{23}$ Michael Drew, ${ }^{24}$ Matthew Freke, ${ }^{25}$ \\ Damian Griffin, ${ }^{26}$ Joshua Heerey (ㄹ, ${ }^{1}$ Per Hölmich, ${ }^{11}$ Franco M Impellizzeri (ㄷ, ${ }^{27}$ \\ Denise M Jones, ${ }^{1}$ Ara Kassarjian, ${ }^{28,29}$ Karim M Khan (1) , ${ }^{30}$ Matthew G King (1) , \\ Peter R Lawrenson, ${ }^{31}$ Michael Leunig, ${ }^{32}$ Cara L Lewis (1), ${ }^{33}$ \\ Kristian Marstrand Warholm, ${ }^{34}$ Michael P Reiman (1), ${ }^{35}$ Adam Semciw, ${ }^{1}$ \\ Kristian Thorborg 다, ${ }^{11}$ Pim van Klij, ${ }^{17}$ Tobias Wörner 다, ${ }^{36}$ Mario Bizzini ${ }^{37}$
}

For numbered affiliations see end of article.

\section{Correspondence to} Dr Joanne L Kemp, La Trobe Sport and Exercise Medicine Research Centre, La Trobe University, Melbourne, Vic, Australia;

j.kemp@latrobe.edu.au

Accepted 30 October 2019 Published Online First 15 November 2019

Check for updates

(C) Author(s) (or their employer(s)) 2020. No commercial re-use. See rights and permissions. Published by BMJ.

To cite: Kemp JL,

Risberg MA, Mosler A,

et al. Br J Sports Med

2020:54:504-511.

\section{ABSTRACT}

The 1st International Hip-related Pain Research Network meeting discussed four prioritised themes concerning hip-related pain in young to middle-aged adults: (1) diagnosis and classification of hip-related pain; (2) patient-reported outcome measures for hip-related pain; (3) measurement of physical capacity for hip-related pain; (4) physiotherapist-led treatment for hip-related pain. Thirty-eight expert researchers and clinicians working in the field of hip-related pain attended the meeting. This manuscript relates to the theme of physiotherapist-led treatments for hip-related pain. A systematic review on the efficacy of physiotherapist-led interventions for hip-related pain (published separately) was conducted and found that strong evidence for physiotherapist-led treatments was lacking. Prior to the meeting, draft consensus recommendations for consideration in the meeting were also developed based on the systematic review. The draft consensus recommendations were presented to all of the meeting participants via email, at least 1 week prior to the meeting. At the meeting, these recommendations were discussed, revised and voted on. Six recommendations for clinical practice and five recommendations for research were included and all gained consensus. Recommendations for clinical practice were that (i) Exercise-based treatments are recommended for people with hip-related pain. (ii) Exercise-based treatment should be at least 3 months duration. (iii) Physiotherapist-led rehabilitation after hip surgery should be undertaken. (iv) Patient-reported outcome measures, measures of physical impairment and measures of psychosocial factors should be used to monitor response to treatment. (v) Physical activity (that may include sport) is recommended for people with hip-related pain. (vi) Clinicians should discuss patient expectations, use shared-decision making and provide education.
Recommendations for research were (i) Reporting of exercise programmes: Exercise descriptors such as load magnitude, number of repetitions and sets, duration of whole programme, duration of contractile element of exercise, duration of one repetition, time under tension, rest between repetitions, range of motion through which the exercise is performed, and rest between exercise sessions should be reported. (ii) Research should investigate the optimal frequency, intensity, time, type, volume and progression of exercise therapy. (iii) Research should examine the effect of patient education in people with hip-related pain. (iv) Research should investigate the effect of other treatments used in people with hip-related pain (for example: manual therapy, medications, injections). (v) Research should examine the impact of comorbidities and social determinants on treatment effectiveness in people with hip-related pain. Clinicians and researchers working with young to middle-aged active adults with hip-related pain may use these consensus recommendations to guide, develop, test and implement individualised, evidence-based physiotherapist-led rehabilitation programmes.

\section{INTRODUCTION}

Hip-related pain is common in young to middleaged active adults (usually aged $18-50$ years) and has a significant impact on physical activity and quality of life. ${ }^{1}$ Pain, physical activity and quality of life, as represented in patient-reported outcome scores, are poor in people with hip-related pain. ${ }^{2-5}$ There are a number of possible presentations relating to hiprelated pain in young to middle aged active adults. ${ }^{1}$ Femoroacetabular impingement (FAI) syndrome is the most common and may be diagnosed in around half of people with hip-related pain. ${ }^{6}$ The diagnosis of FAI syndrome currently includes bony 
morphological changes in the hip which may cause aberrant joint forces during hip movements and possible damage to the intraarticular structures of the joint. ${ }^{1}$ Other causes of hip-related pain can include acetabular dysplasia and intra-articular soft-tissue features such as labral, chondral or ligamentum teres lesions. ${ }^{7}$

The International Hip-related Pain Research Network (IHiPRN) was developed in 2017 to collaborate across research groups and disciplines and disseminate knowledge of hip pain to clinicians. The focus of the IHiPRN specifically relates to 'Hiprelated pain in young to middle aged active adults'. There has been a consensus statement published previously that focused on FAI syndrome as a clinical entity and briefly discussed treatment options for FAI syndrome. ${ }^{1}$ While that consensus statement briefly recommended non-surgical treatments including rehabilitation, it did not specifically discuss evidence-informed recommendations for such treatments. To address this gap, the aim of this paper was to report the recommendations from the IHiPRN consensus meeting for physiotherapist-led treatments that improve pain and function in young to middle aged active adults experiencing hip-related pain.

\section{METHODS}

\section{Literature review}

Prior to the consensus meeting a systematic literature review was conducted in order to provide the evidence summary from which the consensus recommendations contained in this paper were developed. The systematic review was conducted according to the preferred reporting guidelines for systematic reviews and meta-analysis (PRISMA) guidelines and is published separately. ${ }^{8}$ The purpose was to synthesise the evidence of the effect of physiotherapist-led treatment for hip-related pain. Treatment refers to the overall physiotherapist-led management of a patient and is not restricted to any single intervention. Outcomes of interest included patient-reported outcomes of pain, function, activity and quality of life as well as impairment measures such as range of motion (ROM), hip muscle strength, functional task performance and movement quality (including biomechanics). The protocol was registered on the PROSPERO international prospective register of systematic reviews (CRD42018089088) on 20 February 2018. Within the systematic review, evidence was categorised as 'strong' if there were multiple high-quality clinical trials or cohort studies; 'moderate' if there was either one high-quality clinical trial or cohort study and more than two high-quality case-control studies or more than three highquality case-control studies; 'limited' if there were either one or two case-control studies or multiple cross-sectional studies and 'insufficient' if there was not more than one cross-sectional study. ${ }^{9}$

\section{Background and process of the consensus meeting Selection of expert group members}

The IHiPRN leadership group (Joanne Kemp, Kay Crossley, Mario Bizzini, Andrea Mosler, Cara Lewis and Karim Khan) met in January 2017 to identify potential expert group members. Experts were selected based on their track record of publications and being current active researchers in the field of hiprelated pain in young and middle-aged adults. Researchers who were also clinicians in the field were viewed favourably. Potential expert group members were contacted via email asking them to express interest in taking part in the 1st IHiPRN Consensus Meeting in Zurich in November 2018. Potential expert group members were also asked to identify other experts for invitation that the leadership group may not have identified.
Following this expression of interest, four key areas were identified as priorities for consensus. These four key areas were:

I. Classification of hip pain (including use of (i) clinical tests and (ii) imaging).

II. Patient-reported outcome measures for hip pain (including hip-related measures and maybe others including pain/coping/fear/utility measures).

III. Standardised measurement of physical capacity in hiprelated pain (including clinical measures, biomechanics, EMG, physical activity, functional performance and return to sport).

IV. Physiotherapist-led treatment of hip-related pain.

The leadership group then identified experts to lead each working of the four working groups. These were MR and RA (group 1), FI and JK (group 2), AM and CLL (group 3), JK and $\mathrm{MB}$ (group 4). Members of the working groups were then determined following discussion between the leadership group and the working group leaders. The working group members for this paper were Joanne Kemp, Mario Bizzini, Andrea Mosler, Håvard Moksnes, Andreas Serner, May Arna Risberg, Nicolas Mathieu, Boris Gojanovic, Marcie Harris Hayes, Mo Gimpel, Sue Mayes, Kay Crossley, Nancy Bloom, Michael Hunt, Mark Scholes and Lasse Ishøi.

\section{Expert group demographics}

All consensus meeting participants were considered to be experts and at the time of meeting were actively researching in the field of hip-related pain in young and middle-aged active adults. Areas of expertise among the participants included physiotherapy, orthopaedic surgery, sport and exercise medicine, biomechanics, diagnostics, imaging and radiology, patient-reported outcome measures and exercise science. In addition, many of the participants were also expert clinicians who regularly treat young and middle-aged active adults with hip-related pain.

\section{Preagreement meeting process}

Prior to the meeting, a systematic review was undertaken. This formed the evidence summary. ${ }^{8}$ The evidence summaries were revised on multiple occasions by the working groups, prior to a final draft being confirmed. From this, draft consensus recommendations for consideration in the meeting were also developed by the working groups. These evidence summaries and draft consensus recommendations were presented to all of the meeting participants via email, at least 1 week prior to the meeting in Zurich. No voting occurred at this time and experts were provided with this information to allow them to be familiar with the evidence.

\section{Agreement meeting process}

At the beginning of the face to face meeting in Zurich, small breakout groups discussed and revised the evidence summaries where necessary and draft consensus recommendations previously developed. The principal investigators (JLK and MB) then presented the evidence summaries relating to their area to the whole expert group. Participants were then encouraged to discuss each consensus recommendation, and further revisions were then made. At the conclusion of the discussion, each participant was asked to vote on the recommendation, using a 10-point Likert scale, where 0 indicated the statement was considered to be 'inappropriate' and 9 'appropriate'. ${ }^{11}$ Scores were pooled and the median (IQR) for each recommendation was determined. Scores that were $0-3$ were considered inappropriate, scores of 4-6 were considered uncertain and scores of 7-9 were considered appropriate. ${ }^{1011}$ 
The AGREE reporting guidelines have some common elements with this work; however, given the aims of the Zurich meeting, the authors feel that AGREE was not the ideal way to report the results of this topic.

\section{RESULTS}

Results of the consensus meeting

The consensus meeting was held in Zurich, Switzerland on 17 and 18 November 2018 and was attended in person by 37 out of the 44 IHiPRN participants and via videoconferencing by one additional participant. The remaining six participants who did not attend did not participate in voting.

The expert group of 27 physiotherapists, 7 orthopaedic surgeons, 4 sport and exercise medicine physicians, 4 exercise scientists, 1 radiologist and 1 general medical doctor included 12 women and 32 men. The mean(SD) age of participants was 41(11) years and the mean(SD) number of years' experience was 20(10) years. Twenty-one participants were from Europe, 13 from Australia/New Zealand, 8 from North America and 2 from the Middle East. All participants were fluent English speakers.

\section{Consensus recommendations}

The final consensus recommendations and consensus voting results can be found in table 1 and figures 1 and 2 . The consensus group considered all consensus recommendations appropriate. The quality of evidence used to inform the consensus voting ranged from moderate to insufficient. ${ }^{8}$

\section{DISCUSSION}

The 1st International Hip-related Groin Pain Research Network consensus meeting was held in Zurich on 17-18 November 2018. In this paper, we presented the results of the consensus voting on the theme of physiotherapist-led treatment for hiprelated pain. Six recommendations for clinical practice and five recommendations for research were discussed and voted on. These recommendations combine the best available evidence based from the systematic review ${ }^{8}$ with expert opinion. Clinicians working with patients with hip-related pain can use the consensus recommendations to guide physiotherapist-led treatment. Clinicians are encouraged to provide best practice care by integrating these consensus recommendations with their own

Table 1 Summary of final consensus recommendations developed from evidence synthesis for voting at consensus meeting and recommendation of consensus group

\begin{tabular}{|c|c|c|c|c|c|c|c|}
\hline \multicolumn{2}{|c|}{ Consensus recommendations for clinical practice } & \multirow{2}{*}{$\begin{array}{l}\text { Level of evidence } \\
\text { supporting } \\
\text { recommendation }\end{array}$} & \multirow{2}{*}{ Median } & \multirow{2}{*}{$\frac{\mathrm{IQR}}{8-9}$} & \multirow{2}{*}{$\begin{array}{l}\text { Mode } \\
9\end{array}$} & \multirow{2}{*}{$\begin{array}{l}\text { Consensus score } \\
\text { result } \\
\text { Appropriate }\end{array}$} & \multirow{2}{*}{$\begin{array}{l}\text { Number } \\
\text { participants voting } \\
37\end{array}$} \\
\hline C1. & $\begin{array}{l}\text { Exercise-based treatments are recommended for people with } \\
\text { hip-related pain. }\end{array}$ & & & & & & \\
\hline C2. & $\begin{array}{l}\text { Exercise-based treatment should be at least } 3 \text { months } \\
\text { duration. }\end{array}$ & Limited $^{14}$ & 7 & $7-8$ & 7 & Appropriate & 37 \\
\hline C3. & $\begin{array}{l}\text { Physiotherapist-led rehabilitation after hip surgery should be } \\
\text { undertaken. }\end{array}$ & Limited $^{1318}$ & 9 & $8-9$ & 9 & Appropriate & 37 \\
\hline C4. & $\begin{array}{l}\text { PROMs, measures of physical impairment and measures of } \\
\text { psychosocial factors should be used to monitor response to } \\
\text { treatment. }\end{array}$ & Insufficient & 9 & $8-9$ & 9 & Appropriate & 37 \\
\hline C5. & $\begin{array}{l}\text { Physical activity (which may include sport) is recommended } \\
\text { for people with hip-related pain. }\end{array}$ & Insufficient & 9 & $8-9$ & 9 & Appropriate & 37 \\
\hline C6. & $\begin{array}{l}\text { Clinicians should discuss patient expectations, use shared- } \\
\text { decision making and provide education. }\end{array}$ & Insufficient & 9 & $8-9$ & 9 & Appropriate & 37 \\
\hline \multicolumn{2}{|c|}{ Consensus recommendations for Research } & $\begin{array}{l}\text { Level of evidence } \\
\text { supporting } \\
\text { recommendation }\end{array}$ & Median & IQR & Mode & $\begin{array}{l}\text { Consensus score } \\
\text { result }\end{array}$ & $\begin{array}{l}\text { Number of } \\
\text { participants voting }\end{array}$ \\
\hline R1. & $\begin{array}{l}\text { Reporting of exercise programmes. Exercise descriptors such } \\
\text { as: load magnitude, number of repetitions and sets, duration of } \\
\text { whole programme, duration of contractile element of exercise, } \\
\text { duration of one repetition, time under tension, rest between } \\
\text { repetitions, range of motion through which the exercise is } \\
\text { performed and rest between exercise sessions should be } \\
\text { reported. }\end{array}$ & Moderate $^{451214}$ & 9 & 9 & 9 & Appropriate & 36 \\
\hline $\mathrm{R} 2$. & $\begin{array}{l}\text { Development of high-quality exercise programmes. We need } \\
\text { research to investigate the optimal frequency, intensity, time, } \\
\text { type, volume and progression of exercise therapy. }\end{array}$ & Moderate $^{45}$ & 9 & $7-9$ & 9 & Appropriate & 28 \\
\hline R3. & $\begin{array}{l}\text { Research should examine the effect of patient education in } \\
\text { people with hip-related pain. }\end{array}$ & Insufficient* & 8 & $7-9$ & 9 & Appropriate & 36 \\
\hline R4. & $\begin{array}{l}\text { Research should investigate the effect of other treatments } \\
\text { used in people with hip-related pain. }\end{array}$ & Insufficient* & 8 & $8-9$ & 9 & Appropriate & 35 \\
\hline R5. & $\begin{array}{l}\text { Research should examine the impact of comorbidities and } \\
\text { social determinants on treatment effectiveness in people with } \\
\text { hip-related pain. }\end{array}$ & Insufficient* & 9 & 9 & 9 & Appropriate & 36 \\
\hline
\end{tabular}

Scores $0-3$ were considered inappropriate, scores of 4-6 were considered uncertain and scores of 7-9 were considered appropriate.

Not all participants were able to be present for all voting procedures due to other commitments.

${ }^{*}$ Absence of knowledge noted and prioritised as area for future research by expert group.

C, Consensus recommendation for clinical practice;PROMs, patient-reported outcome measures; $\mathrm{R}$, consensus recommendation for research. 


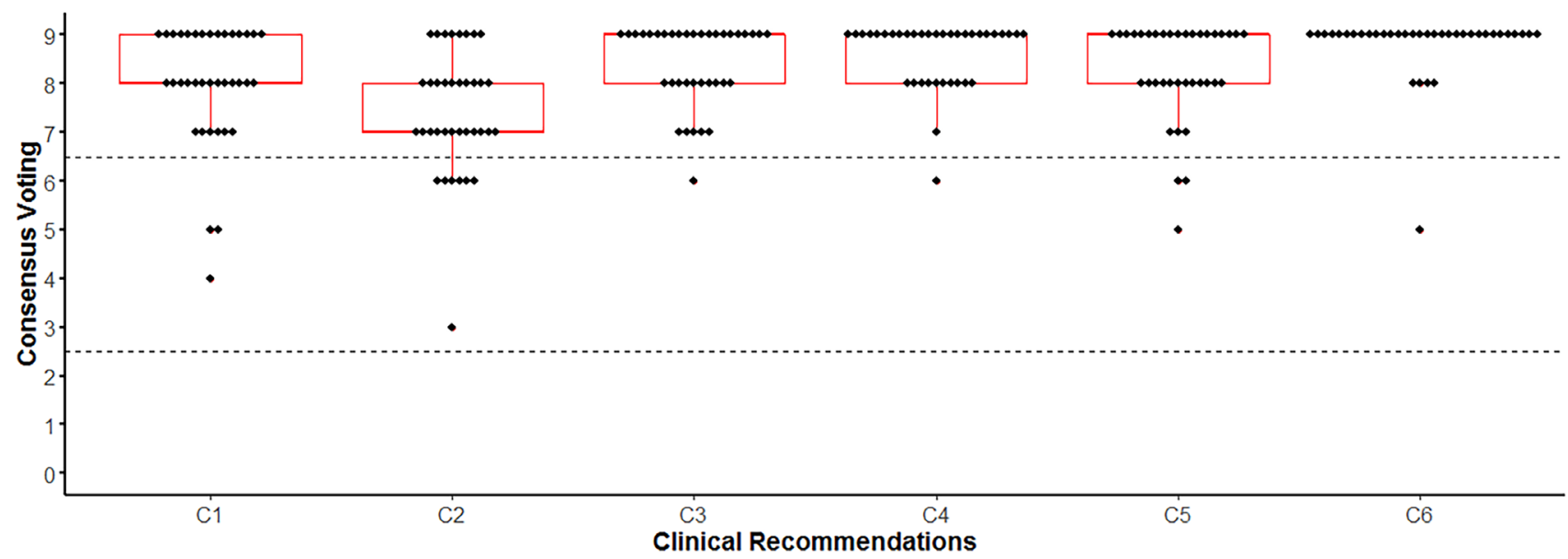

Figure 1 Consensus voting on recommendations for clinical practice $(C) . C 1=$ clinical recommendation $1 ; C 2=c$ linical recommendation 2; C3=clinical recommendation 3; $\mathrm{C} 4=$ clinical recommendation $4 ; C 5=$ clinical recommendation 5; $C 6=$ clinical recommendation 6.

clinical expertise and the individual preferences of the patient in a shared decision-making process regarding treatment options. We anticipate the consensus recommendations for research will provide direction for consistent and transparent future research evaluating physiotherapist-led treatment for hip-related pain. We discuss each of the recommendations below.

\section{Consensus recommendations for clinicians}

C1. Exercise-based treatments are recommended for people with hip-related pain

The level of evidence supporting this statement was moderate 581213 and the median (IQR) score was 8 (1) out of a possible 9 points, indicating small variability within the opinions of the expert group. When undertaking physiotherapist-led treatments in people with hip-related pain, evidence suggests that exercise-based treatments should be prioritised, possibly with hip, trunk and functional strengthening components. ${ }^{8}$ Strengthening or resistance exercise was included in most studies that demonstrated improvements in pain, function and quality of life; however, strengthening alone may not have caused these reported improvements. It is possible that improvements in strength indicate greater capacity of the hip to cope with load as well as promoting self-efficacy and providing graded activity/exposure to challenging activities. There is also support for improving ROM and for functional and movement pattern retraining. ${ }^{12}$ As such, other exercise-based treatments including functional and movement pattern retraining, stretching and ROM exercises could be considered, although the level of evidence to support this is insufficient. Importantly, all studies containing an exercise-based physiotherapist-led treatment showed positive within-group change at follow-up assessment. ${ }^{451214-16}$ The most effective type of exercise, dose of exercise and progression of exercise is not yet known. It is also unclear what constitutes optimal loading in this patient group and what level of pain is acceptable for patients while undertaking physiotherapist-led treatment programmes. Clinicians treating patients with hip-related pain could consider using guidelines for exercise prescription such as those outlined by the American College of Sports Medicine ${ }^{17}$ for the dosage (frequency, intensity, time and type), volume and progression of exercise programmes provided. Future research may consider the development of tools the collection and reporting of load programmes.

C2. Exercise based treatment should be at least 3 months duration The level of evidence supporting this statement was limited, ${ }^{14}$ and the median (IQR) score was 7 (1) out of a possible 9 points. Evidence suggests that physiotherapist-led treatments that were at least 3 months duration had a larger effect compared with studies of shorter duration (ranging from 3 weeks to 7 weeks). It

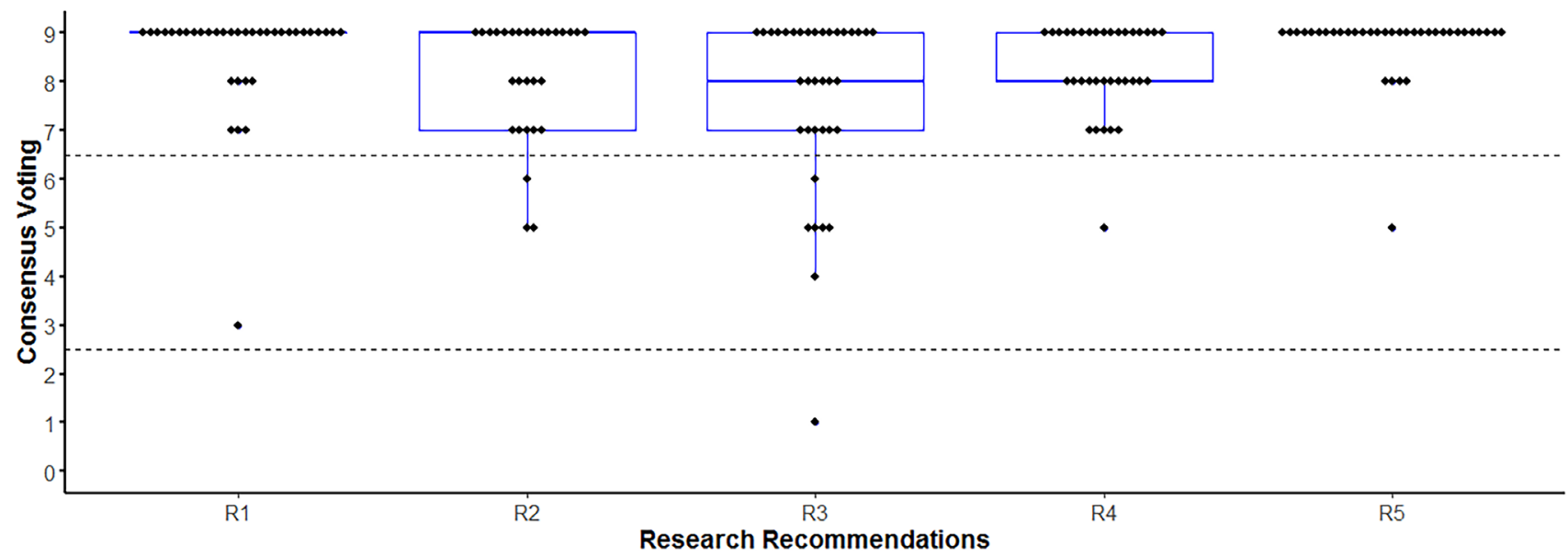

Figure 2 Consensus voting on recommendations for research (R). R1=research recommendation 1; R2=research recommendation 2; R3=research recommendation 3; R4=research recommendation 4; R5=research recommendation 5. 
is uncertain whether improvements would be maintained in the medium- to long-term, as studies with longer follow-up reported more modest within-group improvements for physiotherapist-led treatments. ${ }^{45}$ Further investigation of who is likely to respond to treatment and how to make treatments more targeted to the individual is required.

\section{C3. Physiotherapist-led rehabilitation after hip surgery should be undertaken}

The level of evidence supporting this statement was limited, ${ }^{13} 18$ and the median (IQR) score was 9 (1) out of a possible 9 points, indicating small variability within the opinions of the expert group. Two pilot studies reported improvement in patient outcomes immediately following participation in postoperative rehabilitation. ${ }^{13} 18$ The benefits seen immediately posthip arthroscopy was no longer evident at 6 months follow-up, but 6-month results were likely underpowered. ${ }^{18}$ Full-scale randomised controlled trials (RCTs) are required to determine the efficacy and effectiveness of posthip arthroscopic rehabilitation. Clinicians who provide rehabilitation to patients after hip arthroscopy should consider an individualised approach that targets the specific impairments observed. Previous studies suggest that patients have lower hip and trunk muscle strength, ${ }^{19}$ dynamic balance, ${ }^{20}$ single leg squat alignment, ${ }^{21}$ alterations in gait ${ }^{22}$ and diminished ability to jump, decelerate and perform cutting movements. ${ }^{23}$ following hip arthroscopy These impairments may be appropriate treatment targets in this patient group. In addition, the surgical approach used, and individual surgeon's preference, may also influence the timing and type of rehabilitation needed, and these should be considered on a case-by-case basis. ${ }^{24}$

\section{C4. Patient-reported outcome measures (PROMs), physical} impairment measures and psychosocial factors measures should be used to monitor response to treatment

Despite insufficient evidence, the median (IQR) score for this recommendation was 9 (1) out of a possible 9 points, indicating small variability within the opinions of the expert group. Accurate monitoring of the patient's response to treatment is important to quantify the benefits or not of treatment on the individual patient and may be required by treatment funders in the future. The expert group made recommendations on the most appropriate hip-related PROMs for hip-related pain, which were the Copenhagen Hip and Groin Outcome Score $(\mathrm{HAGOS})^{25}$ and International Hip Outcome Tool (IHOT) ${ }^{26}$ questionnaires. Additionally, measures of physical impairment such as ROM, hip muscle strength, movement quality and functional task performance were also discussed by the expert group and are reported separately.

\section{C5. Physical activity (which may include sport) is recommended for people with hip-related pain}

The level of evidence supporting this statement was insufficient and based solely on the opinion of the expert group; nonetheless, the median (IQR) score was 9 (1) out of a possible 9 points, indicating small variability within the opinions of the expert group. Physical activity is critical for health and may prevent many lifestyle diseases. ${ }^{27}$ Many patients with hip-related pain wish to return to preinjury sport and activity and this is often the reason that they seek treatment. ${ }^{128}$ However, the evidence informing how to enable people with hip-related pain to return to physical activity and sport is scarce, with only two studies in the evidence synthesis including a specific return to sport/return to physical activity component. ${ }^{14} 18$ Despite the lack of evidence, the expert group agreed that physical activities that may assist in returning to sport, physical or occupational activity should be included in physiotherapist-led treatment programmes. In collaboration with the patient, sport or activity specific goals should be developed and strategies to achieve these goals implemented in the physiotherapist-led treatment programme. In the absence of evidence specifically related to this patient group in assessing readiness, and in guiding, monitoring and progressing return to sport, the guidelines recommended using the 2016 consensus statement on return to sport. ${ }^{29}$ Treatment targeting return to physical activity and sport should be individualised to the type and level of function to which the patient wishes to return and consider patient preferences. If the patient wishes to successfully return to sport, the ability to safely and confidently tolerate high loads in the hip joint should be considered and planned for. This may include initially focusing on strength, cardiovascular fitness, basic athletic movements and the ability to tolerate load, then gradually introducing sports-specific highlevel tasks, which may include running, high speed running, twisting, turning and moving into provocative positions at high speed. It is important during this process that individual patient's symptoms are respected, although it is unknown whether symptoms during sport are related to long-term joint health.

\section{C6. Clinicians should discuss patient expectations, use shared- decision making and provide education}

The level of evidence supporting this statement was insufficient and based solely on the opinion of the expert group, however the median (IQR) score was $9(0)$ out of a possible 9 points, indicating almost no variability within the opinions of the expert group. Informing patients of their health condition, treatment choices, possible benefits and harms of each treatment option, and the likely outcome if no treatment is undertaken is important for many patients to engage in the shared decision-making process. ${ }^{30}$ Clinicians should determine the health literacy of the individual patient and tailor the information to suit. Education may be a critical element of shared decision-making. Strategies, such as asking the patient to repeat the information back to you, using oral, written and visual educational tools, inviting the patient's support person to participate in the process, and encouraging questions may assist in engaging patients in the education process. ${ }^{3132}$ The expert group indicated that motivational interviewing could be included, but was not critical to engaging patients in the shared decision-making process. Key points to discuss with patients to facilitate realistic expectations regarding treatment outcomes may include (i) the associated risks of surgical and nonsurgical options; (ii) the likely magnitude of improvement and (iii) the likely duration and cost. In addition, the relationship between pain and hip joint structure (including the prevalence of morphological and intra-articular findings in asymptomatic people) ${ }^{7}$ should be discussed with the patient.

\section{Consensus recommendations for research}

R1. Reporting of exercise programmes. Exercise descriptors such as load magnitude, number of repetitions and sets, duration of whole programme, duration of contractile element of exercise, duration of one repetition, time under tension, rest between repetitions, range of motion through which the exercise is performed and rest between exercise sessions should be considered and reported. The level of evidence supporting this statement was moderate, where in the systematic review, one high quality $\mathrm{RCT}^{5}$ one moderate quality RCT ${ }^{4}$ and two high quality pilot RCTs ${ }^{12} 14$ did not report these descriptors adequately. The median (IQR) score was $9(0)$ out of a possible 9 points, indicating almost no variability within the opinions of expert group. The primary goal of studies 
examining physiotherapist-led exercise therapies for hip-related pain is to develop and then test the most effective exercises for the condition. When developing effective and tailored treatment programmes, the mechanistic effect of particular elements of the exercises on the target muscles and surrounding tissues is considered. Toigo and Boutellier ${ }^{33}$ described principles to be considered in the development and reporting of exercise programmes. These included load magnitude, number of repetitions and sets, duration of whole programme, duration of contractile element of exercise (ie, how long the concentric, eccentric or isometric component of the repetition should take), duration of one repetition, time under tension (ie, the overall time the muscle is under tension during the set), rest duration between repetitions, ROM through which the exercise is performed and rest duration between exercise sessions. ${ }^{24} 33$ When reporting (and developing) exercise-based interventions, we also recommended using the Consensus on Exercise Reporting Template (CERT) ${ }^{34}$ and Template for Intervention Description and Replication (TIDieR) checklist. ${ }^{35}$ Improved reporting of programmes is critical to move forward in the quality of physiotherapist-led treatments provided to patients with hip-related pain.

\section{R2. Development of high-quality exercise programmes. Research should investigate the optimal frequency, intensity, time, type, volume and progression of exercise therapy}

The level of evidence supporting this statement was moderate. One high quality $\mathrm{RCT}^{5}$ and one moderate quality $\mathrm{RCT}^{4}$ did not describe the physiotherapist-led exercise programme adequately. The median (IQR) score was 9 (2) out of a possible 9 points, indicating some variability within the opinions of expert group. Exercise-based programmes used in clinical research should include patient input in their design and be appropriately constructed to gain maximal improvements in outcomes. In strength-based treatments, exercise programme require adequate load to gain a strength effect. The frequency, intensity, time, type, volume and progression of exercise therapy may need to be manipulated to gain the desired effect. The expert group recommended that guidelines, such as those developed by the American College of Sports Medicine (ACSM), should be used with the development of strength-based treatments. ${ }^{17}$ The group also indicated that fidelity and adherence of exercise programmes were often not suitable to gain the desired effect. ${ }^{36}$ Studies evaluating the effectiveness of physiotherapist-led exercise programmes should ensure that treatments are developed and reported using these principles.

\section{R3. Research should examine the effect of patient education in people with hip-related pain}

The level of evidence supporting this statement was insufficient and based solely on the opinion of the expert group and the median (IQR) score was 8 (2) out of a possible 9 points, indicating some variability within the opinions of the expert group. To our knowledge, no studies have investigated patient education in people with hip-related pain. We recommended that future studies assess the specific effect of patient education for hip-related pain including content, modes of delivery and the use of innovative technologies to enhance education benefits.

\section{R4. Research should investigate the effect of other treatments used in people with hip-related pain}

There was no evidence to our knowledge supporting this statement and so was based solely on the opinion of the expert group, with the median (IQR) score was 8 (1) out of a possible
9 points, indicating small variability within the opinions of the expert group. Hip joint intra-articular injections, ${ }^{37}$ analgesic and anti-inflammatory medications, manual therapy adjunctive techniques such as taping, bracing and orthotics might be used by clinicians; however, their rate of use and clinical effectiveness is unknown. Although the group acknowledged that clinical treatment of hip-related pain is generally multimodal, these adjunct therapies should not replace exercise-based treatment. Further research is required to determine the frequency of use and the effectiveness of adjunct therapies used for hip-related pain.

R5. Research should examine the impact of comorbidities and social determinants on treatment effectiveness in people with hip-related pain

The level of evidence supporting this statement was insufficient and based solely on the opinion of the expert group; however, the median (IQR) score was $9(0)$ out of a possible 9 points, indicating almost no variability within the opinions of the expert group. The expert group indicated that comorbidities and social determinants (eg, socioeconomic status, education level) can influence the patient's prognosis as well as the effectiveness of treatment. Comorbidities including chronic pain, insomnia and anxiety increased following hip arthroscopy surgery, although causation was not implied. ${ }^{38}$ To date, no studies examining physiotherapist-led treatment for hip-related pain have determined whether comorbidities influence the outcome of treatment or whether they change with treatment. These factors should be examined in future studies exploring physiotherapist-led treatment for hip-related pain.

\section{LIMITATIONS}

There are a number of limitations in this paper that should be acknowledged. Importantly, the range of the age and years of experience of the participants in the expert group was varied. All participants who comprised the expert group were from Europe, North America and Australia/New Zealand. This probably limited the cultural diversity and consideration in the discussions. Future meetings could consider inviting experts from all global regions. While every effort was made to include a balance of female and male participants in the expert group, there were more men than women. Future meetings should also attempt to improve gender diversity as well as other types of diversity. Finally, the consensus was limited by the amount and quality of published evidence. The recommendations for future research may help improve the evidence available for future meetings.

\section{CONCLUSION}

Prior to the 1st IHiPRN consensus meeting, a working group developed and gained consensus on six evidence-informed recommendations for clinical practice and five recommendations for research. At the meeting, 38 experts in the field of hiprelated pain discussed and voted on consensus recommendations relating to physiotherapist-led treatments for hip-related pain. Clinicians and researchers working with young to middle-aged adults with hip-related pain can use the consensus recommendations to best guide, develop, implement and test individualised, evidence-based physiotherapist-led treatment programmes.

\footnotetext{
Author affiliations

${ }^{1}$ La Trobe Sports Exercise Medicine Research Centre, School of Allied Health, Human Services and Sport, College of Science, Health and Engineering, La Trobe University, Melbourne, Victoria, Australia

${ }^{2}$ Department of Sport Medicine, Norwegian School of Sport Sciences, Oslo, Norway

${ }^{3}$ Division of Orthopedic Surgery, Oslo University Hospital, Oslo, Norway
} 
${ }^{4}$ Physical Therapy, Washington University School of Medicine in Saint Louis, Saint Louis, Missouri, USA

${ }^{5}$ Orthopaedic Surgery, Washington University School of Medicine in Saint Louis, Saint Louis, Missouri, USA

${ }^{6}$ Aspetar Orthopaedic and Sports Medicine Hospital, Doha, Qatar

${ }^{7}$ Oslo Sports Trauma Research Center, Oslo, Norway

${ }^{8}$ Swiss Olympic Medical Center, Hopital de la Tour, Meyrin, Geneva, Switzerland

${ }^{9}$ SportAdo consultation, University Hospital of Lausanne (CHUV) Multidisciplinary

Unit of Adolescent Health, Lausanne, Switzerland

${ }^{10}$ Department of Physical Therapy, University of British Columbia, Vancouver, British

Columbia, Canada

${ }^{11}$ Sports Orthopaedic Research Center-Copenhagen (SORC-C), Department of

Orthopedic Surgery, Copenhagen University Hospital, Amager-Hvidovre, Denmark

${ }^{12}$ Physiotherapy, HES-SO Valais, University of Applied Sciences Western Switzerland,

Leukerbad, Valais, Switzerland

${ }^{13}$ The Australian Ballet, Southbank, Victoria, Australia

${ }^{14}$ Performance Science, Southampton Football Club, Southampton, UK

${ }^{15}$ Monash School of Medicine, Monash University, Melbourne, Victoria, Australia

${ }^{16}$ Department of Health Sciences, Lund University, Lund, Sweden

${ }^{17}$ Department of Orthopaedic Surgery, University Medical Centre Rotterdam,

Rotterdam, The Netherlands

${ }^{18}$ Human Performance Lab, Schulthess Clinic, Zurich, Switzerland

${ }^{19}$ Laboratory of Exercise and Health, ETH Zurich, Schwerzenbach, Switzerland

${ }^{20}$ Griffith Centre of Biomedical and Rehabilitation Engineering (GCORE, Menzies

Health Institute Queensland Griffith University, School of Allied Health Sciences, Gold

Coast, Queensland, Australia

${ }^{21}$ Department for Continuing Education, University of Oxford, Oxford, UK

${ }^{22}$ Aspetar Sports Medicine Hospital, Doha, Qatar

${ }^{23}$ Division of Physical Therapy, The Ohio State Univesity, Columbus, Ohio, USA

${ }^{24}$ University of Canberra Research into Sport and Exercise (UCRISE), University of

Canberra, Canberra, Australian Capital Territory, Australia

${ }^{25}$ School of Health \& Rehabilitation Sciences, The University of Queensland, Brisbane, Queensland, Australia

${ }^{26}$ Warwick Orthopaedics, University of Warwick, Coventry, UK

${ }^{27}$ Faculty of Health, University of Technology Sydney, Sydney, New South Wales, Australia

${ }^{28}$ Musculoskeletal Radiology, Corades, LLC, Brookline, Massachusetts, USA

${ }^{29}$ Musculoskeletal Radiology, Elite Sports Imaging, SL, Madrid, Spain

${ }^{30}$ Family Practice \& Kinesiology, The University of British Columbia, Vancouver, British Columbia, Canada

${ }^{31}$ School of Health \& Rehabilitation Sciences, University of Queensland, Brisbane, Queensland, Australia

${ }^{32}$ Department of Orthopaedics, Schulthess Klinik, Zurich, Switzerland

${ }^{33}$ Physical Therapy \& Athletic Training, Boston University, Boston, Massachusetts, USA

${ }^{34}$ Divisionof Ortopeadic Surgery, Oslo University Hospital, Oslo, Norway

${ }^{35}$ Orthopedic Surgery, Duke University Medical Center, Durham, North Carolina, USA

${ }^{36}$ Department of Health Sciences, Lunds University, Lund, Sweden

${ }^{37}$ Schulthess Clinic Human Performance Lab, Zurich, Switzerland

Correction notice This article has been corrected since it published Online First. The author affiliations have been updated.

Twitter Joanne L Kemp @JoanneLKemp, Andrea Mosler @AndreaBMosler, Marcie Harris-Hayes@MHarrisHayes, Andreas Serner @aserner, Håvard Moksnes @ HMoksnes, Boris Gojanovic @drsportsante, Lasse Ishøi @Lasselshoei, Mark J Scholes @MarkScholes85, Mo Gimpel @MoGimpel, Daniel Friedman @ddfriedman, Eva Ageberg @EvaAgeberg, Rintje Agricola @RintjeAgricola, Nicola C Casartelli @ NicCasartelli, Laura E Diamond @lauradiamond05, Michael Drew @ mickdrew, Damian Griffin @DamianGriffin, Joshua Heerey @JHeerey, Franco M Impellizzeri @ francoimpell, Ara Kassariian @akassarjian, Matthew G King @mattgmking1, Cara L Lewis@ProfCaraLewis, Michael P Reiman @MikeReiman, Adam Semciw @ASemciw, Kristian Thorborg @KThorborg and Tobias Wörner @Wuninho

Contributors The concept was developed by JK, AM, KMC, KMK, CLL and MB. All authors contributed to the material presented and approved the final version of the manuscript.

Funding Dr Kemp is supported by an NHMRC (Australia) ECF 1119971

Competing interests None declared.

Patient consent for publication Not required.

Provenance and peer review Not commissioned; externally peer reviewed.

Data availability statement Data are available on request

\section{ORCID iDs}

Joanne L Kemp http://orcid.org/0000-0002-9234-1923

Marcie Harris-Hayes http://orcid.org/0000-0003-4274-1651

Andreas Serner http://orcid.org/0000-0003-4308-901X
Kay M Crossley http://orcid.org/0000-0001-5892-129X

Boris Gojanovic http://orcid.org/0000-0001-5075-9371

Lasse Ishøi http://orcid.org/0000-0002-2716-6567

Eva Ageberg https://orcid.org/0000-0002-8639-3006

Nicola C Casartelli http://orcid.org/0000-0002-1280-866X

Laura E Diamond http://orcid.org/0000-0002-2197-1856

Joshua Heerey http://orcid.org/0000-0001-8691-1830

Franco M Impellizzeri http://orcid.org/0000-0002-1703-2573

Karim M Khan http://orcid.org/0000-0002-9976-0258

Matthew G King http://orcid.org/0000-0003-0470-5924

Cara L Lewis https://orcid.org/0000-0002-9888-4902

Michael P Reiman http://orcid.org/0000-0003-4557-3446

Kristian Thorborg http://orcid.org/0000-0001-9102-4515

Tobias Wörner http://orcid.org/0000-0001-5555-0876

\section{REFERENCES}

1 Griffin DR, Dickenson EJ, O'Donnell J, et al. The Warwick agreement on femoroacetabular impingement syndrome (FAl syndrome): an international consensus statement. Br J Sports Med 2016;50:1169-76.

2 Kierkegaard S, Langeskov-Christensen M, Lund B, et al. Pain, activities of daily living and sport function at different time points after hip arthroscopy in patients with femoroacetabular impingement: a systematic review with meta-analysis. $\mathrm{Br} J$ Sports Med 2017;51:572-9

3 Thorborg K, Kraemer O, Madsen A-D, et al. Patient-Reported outcomes within the first year after hip arthroscopy and rehabilitation for femoroacetabular impingement and/ or Labral injury: the difference between getting better and getting back to normal. Am J Sports Med 2018;46:2607-14.

4 Griffin DR, Dickenson EJ, Wall PDH, et al. Hip arthroscopy versus best conservative care for the treatment of femoroacetabular impingement syndrome (UK fashion): a multicentre randomised controlled trial. The Lancet 2018:391:2225-35.

5 Mansell NS, Rhon DI, Meyer J, et al. Arthroscopic surgery or physical therapy for patients with femoroacetabular impingement syndrome: a randomized controlled trial with 2-year follow-up. Am J Sports Med 2018;46:1306-14.

6 Mascarenhas VV, Rego P, Dantas P, et al. Imaging prevalence of femoroacetabular impingement in symptomatic patients, athletes, and asymptomatic individuals: a systematic review. Eur J Radiol 2016;85:73-95.

7 Reiman MP, Agricola R, Kemp JL, et al. Consensus recommendations on the classification, definition and diagnostic criteria of hip-related pain in young and middle-aged active adults from the International Hip-related pain research network, Zurich 2018. Br J Sports Med 2019. Under review.

8 Kemp JL, Mosler AB, Hart HF, et al. Reducing pain and improving function in people with hip-related pain: a systematic review and meta-analysis of physiotherapist-led interventions for hip-related pain. Br J Sports Med 2019. Under review.

9 van Tulder M, Furlan A, Bombardier C, et al. Updated method guidelines for systematic reviews in the Cochrane collaboration back review group. Spine 2003;28:1290-9.

10 Collins NJ, Barton CJ, van Middelkoop M, et al. 2018 consensus statement on exercise therapy and physical interventions (orthoses, taping and manual therapy) to treat patellofemoral pain: recommendations from the 5th International Patellofemoral pain research retreat, gold Coast, Australia, 2017. Br J Sports Med 2018:52:1170-8.

11 Crossley KM, van Middelkoop M, Callaghan MJ, et al. 2016 Patellofemoral pain consensus statement from the 4th International Patellofemoral pain research retreat, Manchester. Part 2: recommended physical interventions (exercise, taping, bracing, foot orthoses and combined interventions). Br J Sports Med 2016;50:844-52.

12 Harris-Hayes M, Czuppon S, Van Dillen LR, et al. Movement-Pattern training to improve function in people with chronic hip joint pain: a feasibility randomized clinica trial. J Orthop Sports Phys Ther 2016:46:452-61.

13 Kemp J, Moore K, Fransen M, et al. A pilot randomised clinical trial of physiotherapy (manual therapy, exercise, and education) for early-onset hip osteoarthritis post-hip arthroscopy. Pilot Feasibility Stud 2018;4.

14 Kemp JL, Coburn SL, Jones DM, et al. The physiotherapy for femoroacetabular impingement rehabilitation study (physioFIRST): a pilot randomized controlled trial. $J$ Orthop Sports Phys Ther 2018;48:307-15.

15 Grant LF, Cooper DJ, Conroy JL. The HAPI 'Hip Arthroscopy Pre-habilitation Intervention' study: does pre-habilitation affect outcomes in patients undergoing hip arthroscopy for femoro-acetabular impingement? J Hip Preserv Surg 2017;50:hnw046-92

16 Wright AA, Hegedus EJ, Taylor JB, et al. Non-Operative management of femoroacetabular impingement: a prospective, randomized controlled clinical tria pilot study. Journal of Science and Medicine in Sport 2016:19:716-21.

17 Medicine ACOS. ACSM's guidelines for exercise testing and prescription. 10th edn. Philadelphia, PA: Wolters Kluwer/Lippincott Williams \& Wilkins, 2017.

18 Bennell KL, Spiers L, Takla A, et al. Efficacy of adding a physiotherapy rehabilitation programme to arthroscopic management of femoroacetabular impingement syndrome: a randomised controlled trial (fair). BMJ Open 2017:7:e014658.

19 Freke M, Kemp JL, Svege I, et al. Physical impairments in symptomatic femoroacetabular impingement: a systematic review of the evidence. $\mathrm{Br}$ J Sports Med 2016;50:1180. 
20 Hatton AL, Kemp JL, Brauer SG, et al. Impairment of dynamic Single-Leg balance performance in individuals with hip Chondropathy. Arthritis Care Res 2014;66:709-16.

21 Charlton PC, Bryant AL, Kemp JL, et al. Single-Leg squat performance is impaired 1 to 2 years after hip arthroscopy. Pm $R$ 2016;8:321-30.

22 Brisson N, Lamontagne M, Kennedy MJ, et al. The effects of CAM femoroacetabular impingement corrective surgery on lower-extremity gait biomechanics. Gait Posture 2013:37:258-63.

23 Domb BG, Dunne KF, Martin TJ, et al. Patient reported outcomes for patients who returned to sport compared with those who did not after hip arthroscopy: minimum 2-year follow-up. J Hip Preserv Surg 2016;3:124-31.

24 Heerey J, Risberg MA, Magnus J, et al. Impairment-Based rehabilitation following hip arthroscopy: postoperative protocol for the hip arthroscopy international randomized controlled trial. J Orthop Sports Phys Ther 2018;48:336-42.

25 Thorborg K, Holmich P, Christensen R, et al. The Copenhagen hip and groin outcome score (HAGOS): development and validation according to the COSMIN checklist. Br J Sports Med 2011;45:478-91.

26 Mohtadi NGH, Griffin DR, Pedersen ME, et al. The development and validation of a self-administered quality-of-life outcome measure for young, active patients with symptomatic hip disease: the International hip outcome tool (iHOT-33). Arthroscopy 2012;28:595-610.

27 Reiner M, Niermann C, Jekauc D, et al. Long-term health benefits of physical activity-a systematic review of longitudinal studies. BMC Public Health 2013;13:813.

28 Ishoi L, Thorborg K, Kraemer O, et al. Return to sport and performance after hip arthroscopy for femoroacetabular impingement in 18- to 30-year-old athletes: a cross-sectional cohort study of 189 athletes. Am J Sports Med 2018;363546518789070.
29 Ardern CL, Glasgow P, Schneiders A, et al. 2016 consensus statement on return to sport from the first world Congress in sports physical therapy, Bern. Br J Sports Med 2016;50:853-64.

30 Friedman DJ, Khan KM. Preventing overdiagnosis and the harms of too much sport and exercise medicine. Br J Sports Med 2019;53:1314-8.

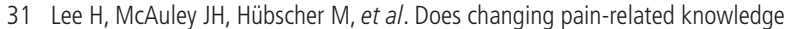
reduce pain and improve function through changes in catastrophizing? Pain 2016;157:922-30

32 Louw A, Diener I, Butler DS, et al. The effect of neuroscience education on pain, disability, anxiety, and stress in chronic musculoskeletal pain. Arch Phys Med Rehabil 2011;92:2041-56

33 Toigo M, Boutellier U. New fundamental resistance exercise determinants of molecular and cellular muscle adaptations. Eur J App/ Physiol 2006;97:643-63.

34 Slade SC, Dionne CE, Underwood M, et al. Consensus on exercise reporting template (CERT): explanation and elaboration statement. Br J Sports Med 2016:50:1428-37.

35 Hoffmann TC, Glasziou PP, Boutron I, et al. Better reporting of interventions: template for intervention description and replication (TIDieR) checklist and guide. BMJ 2014;348.

36 Holden S, Rathleff MS, Jensen MB, et al. How can we implement exercise therapy for patellofemoral pain if we don't know what was prescribed? A systematic review. $\mathrm{Br} J$ Sports Med 2018;52:385.

37 Khan W, Khan M, Alradwan H, et al. Utility of intra-articular hip injections for femoroacetabular impingement. Orthop J Sports Med 2015;3.

38 Rhon DI, Greenlee TA, Marchant BG, et al. Comorbidities in the first 2 years after arthroscopic hip surgery: substantial increases in mental health disorders, chronic pain, substance abuse and cardiometabolic conditions. Br J Sports Med 2019;53:547-53 